Article

\title{
Optimal Capacity Configuration for Energy Hubs Considering Part-Load Characteristics of Generation Units
}

\author{
Shan Deng ${ }^{1}{ }^{(0)}$, Qinghua $W u^{1, *}$, Zhaoxia Jing ${ }^{1}$, Lilan $W u^{1}$, Feng Wei ${ }^{1}$ and Xiaoxin Zhou ${ }^{2}$ \\ 1 School of Electric Power Engineering, South China University of Technology, Guangzhou 510640, China; \\ deng.shan@mail.scut.edu.cn (S.D.); zxjing@scut.edu.cn (Z.J.); wu.lilan@mail.scut.edu.cn (L.W.); \\ w.f15@mail.scut.edu.cn (F.W.) \\ 2 China Electric Power Research Institute, State Grid Corporation of China, Qinghe, Beijing 100192, China; \\ xxzhou@epri.sgcc.com.cn \\ * Correspondence: wuqh@scut.edu.cn; Tel.: +86-020-3938-1199
}

Received: 29 September 2017; Accepted: 16 November 2017; Published: 25 November 2017

\begin{abstract}
The simulation model is one of the key points affecting the optimal planning and operation of energy hubs (EHs). Since treating the efficiencies of generation units as constants would significantly simplify the calculation, only a simplified model is investigated in most research works. In this paper, aiming at optimizing the capacity configuration of an $\mathrm{EH}$, we present a part-load characteristics-based (PLCB) model, in which the efficiencies of generation units will change with the fluctuating load. Based on the PLCB model, the accuracy of the EH model can be improved. Furthermore, a two-stage planning method is proposed to solve the optimal capacity configuration problem of the EH. Group Search Optimizer (GSO) is used to determine the optimal size in the first stage, and a mathematical programming method is applied to obtain the optimal operation of the EH in the second stage. Comparative studies using the PLCB model and the simplified model are performed to examine the impacts of equipment part-load characteristics on the sizing results. Simulation results indicate that the proposed model appears to have a better economic performance than the simplified model.
\end{abstract}

Keywords: energy hubs; simplified model; capacity configuration; part-load characteristics-based model; two-stage planning method

\section{Introduction}

The most significant concerns for the comprehensive utilization of energy resources are the exponential growth of energy requirements and environmental pollution [1-5]. Energy hubs play an important role in implementing the integrated energy system as an interconnection point between various energy components and networks. Over the past few years, many researchers have put the concept of the energy hub (EH) into use for facilitating the analysis of multiple energy carrier flows and their interactions [6-12]. In most of the articles, EHs performed the same function as a combined cooling heating and power (CCHP) system. This may be due to the fact that the EHs are commonly applied to a district energy system supplying energy directly to the end users. For example, a mathematical optimization model of a residential EH considering the human comfort factors was presented in Ref. [13], aiming at minimizing the total cost of electricity and gas. Then on this basis, the smart energy hub, in which the customers can participate in the integrated demand response program by choosing different ways of energy supply was proposed in Ref. [14]. In addition, the renewable energy, as well as the uncertainty factors were taken into consideration when managing a residential EH [15,16]. 
Generally, reasonable planning is an important premise and guarantee for the stable and efficient operation of EHs. To address the issues related to the optimal planning of EHs, a lot of research works have been proposed. For instance, it has been verified that the appropriate sizing is one of the most important issues for a cost-effective energy system [17]. An incorporated model in which the sizing optimization can be accomplished technically and economically according to the system reliability requirements was proposed in Ref. [18]. In terms of the more complex energy systems, a co-optimization method was presented to determine the optimal operation strategy along with the optimal system configurations, indicating that the new structured CCHP system performs much better than the conventional separate system in the annual cost of the CCHP [19]. When taking the influence of the shortage of energy supplies into consideration, the results showed that the economy of the system would be improved if we design the system considering tolerance for energy supply shortages [20].

However, a common feature of the aforementioned optimization models is that the energy systems are formulated as linear models, ignoring the nonlinear feature of generation units. The operation of EHs poses a quantity of challenges, which are mainly caused by the fluctuating heating, cooling and electricity demands that the EHs face. Hence, the part-load characteristics are the common conditions encountered in the operation of generation units. As mentioned above, a large number of mathematical models of EHs has been developed to achieve the goal of better economic performance, amongst which, the key difference lies in the methods for dealing with the part-load characteristics of energy converters in the EHs. The energy converters in the EHs are often modelled simply. For instance, most of these models neglect the variations of efficiency or the coefficient of performance (COP) whilst operating at part-load levels. The tri-commodity simplex (TCS) algorithm was proposed to solve the hourly trigeneration problem when treating the equipment efficiencies as constants [21], and a linear programming was presented for determining the optimal operation mode corresponding to the lowest variable cost [22]. In fact, the assumption in which the equipment efficiencies are constants may lead to inaccurate results in terms of the operation strategy. In addition, the adopted operation strategy is a key factor affecting the optimal planning of EHs. Hence, the part-load characteristics of components in EHs should be taken into consideration in terms of the planning of EHs.

The optimal capacity configurations of EHs is closely and inseparably related to the optimal scheduling of EHs. However, most of these optimal planning and design studies failed to take all of the factors relative to the performance of the system into account, including the capacity of each generation unit, the part-load characteristics of converters, the operation strategy, and so on. Unlike the previous work, this paper presents a two-stage method for the optimal capacity configuration of EHs considering all the aforementioned factors. In the first stage, GSO is applied to solve the optimal capacity configuration problem of generation units in the EH. The objective function is the life cycle cost of the system. In the second stage, a mixed integer nonlinear programming (MINLP) method is used to obtain the optimal operation strategy when taking into account the part-load characteristics of all key equipment in the $\mathrm{EH}$.

It is worth mentioning that the EH considered in this paper is applied directly to the end users with a typical structure, from which the cooling, electricity and heating are supplied simultaneously. In addition to the operation and maintenance cost, the residual cost of the generation units and the emission cost caused by the consumption of electricity and natural gas are also taken into consideration in this paper. Afterwards, aiming at evaluating the impacts of the part-load characteristics of generation units on the capacity configuration of an $\mathrm{EH}$, two test cases are conducted on the part-load characteristics-based (PLCB) model of the EH with profit-oriented operation mode and heat load following mode. Compared to the existing literature, the main contributions of the this paper can be divided into two aspects. On the one hand, this paper proposes a two-stage optimal method to solve the EHs capacity configuration problem. On the other hand, this paper investigates the effects of the part-load characteristics of generation units on the optimal capacity configuration of EHs. 
The following parts of this paper are organized as follows. Section 2 describes the part-load characteristics of an EH. Then, a two-stage optimization method for solving the capacity configuration of the EH is presented in Section 3. Two test cases are carried out on the PLCB model and the simplified model in Section 4. Section 5 compares the difference of the optimal capacity configuration and operation strategy of the EH between the two models. Finally, Section 6 draws the conclusions.

\section{Mathematical Model for an EH}

A schematic diagram of a typical EH is depicted in Figure 1. The EH consists of the energy supply side, the generation units' side and the end users' side. As shown in Figure 1, the energy supply side is composed of the utility grid and natural gas. As for the generation units' side, the gas turbine (GT), heat recovery steam generator (HRSG), gas boiler (GB), electric chiller (EC), absorption chiller (AC) and heat exchanger (HE) are included in this system. Besides, the end users' side consists of the electric demand, cooling demand and heating demand. In this section, the mathematical models of the EH, including the PLCB model and simplified model, are provided.

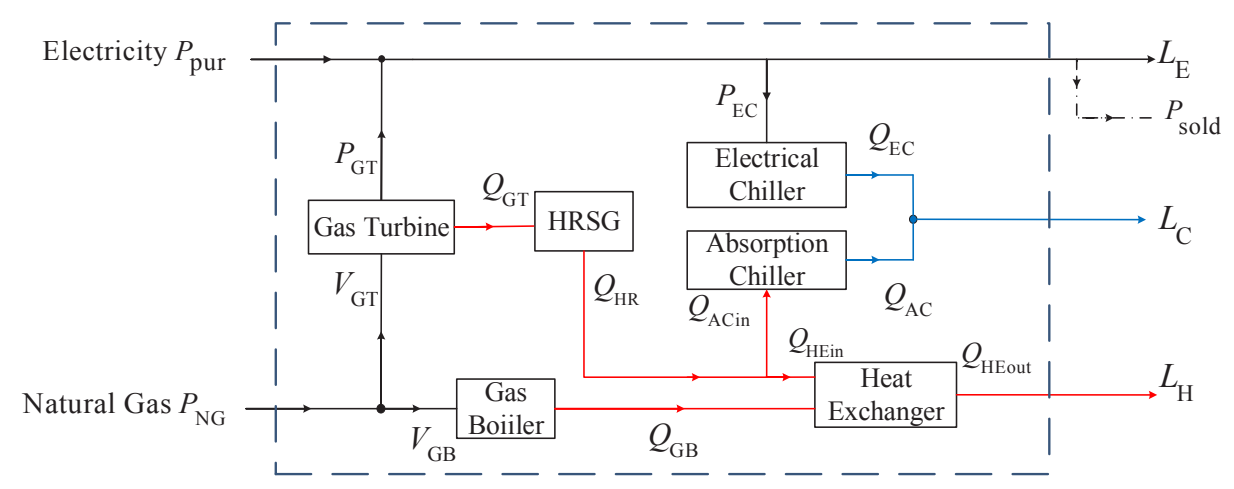

Figure 1. Schematic diagram of an energy hub.

\subsection{PLCB Model}

It is worth mentioning that the equipment's performance curves are obtained from the related documents $[23,24]$, and the detailed depiction of the general form of the models is presented in the following.

\subsubsection{Gas Turbine}

In the $\mathrm{EH}, \mathrm{GT}$ is used as the power generation unit for simultaneously producing electricity and recoverable heat. On the one hand, the electricity is used to satisfy part of the electric demand, as well as to drive the electric chiller. The shortage of electricity can be supplemented by the public grid when the electricity produced by GT is insufficient. On the contrary, the excess electricity can be sold back to the grid when the electricity generated by GT is more than the demand. When taking the part-load characteristics of GT into consideration, the output power of electricity and the amount of gas fuel consumption are directly determined by the amount of thermal output. As a consequence, the GT performances based on the part-load characteristics are formulated as follows [24]:

$$
\begin{gathered}
P_{\mathrm{GT}}^{t}=K_{1}\left(Q_{\mathrm{GT}}^{t}\right)^{2}+K_{2} Q_{\mathrm{GT}}^{t}+K_{3} \\
P_{\mathrm{NG}}^{t}=K_{4}\left(Q_{\mathrm{GT}}^{t}\right)^{2}+K_{5} Q_{\mathrm{GT}}^{t}+K_{6} \\
V_{\mathrm{GT}}^{t}=\frac{P_{\mathrm{NG}}^{t}}{\mathrm{LHV}}
\end{gathered}
$$


where $P_{\mathrm{GT}}^{t}$ and $Q_{\mathrm{GT}}^{t}$ denote the output power and heat of the gas turbine at time $t$, respectively. $P_{\mathrm{NG}}^{t}$ represents the power produced by natural gas at time $t$. LHV refers to the lower heating value of gas. $V_{\mathrm{GT}}^{t}$ is the gas consumption of GT at time $t$. $K_{1}-K_{6}$ are fitting constants.

\subsubsection{Heat Recovery Steam Generator}

The heat recovery steam generator is widely used in cogeneration cycle systems due to the ability to recover high-grade waste heat and further improve energy efficiency [25]. In general, HRSG recovers the waste heat generated by GT. A part of the waste heat is applied to drive the absorption chiller, and the other part is used to turn the ordinary water into the hot water we need. In practice, the HRSG is often operated under different parameters due to the temperature of the steam demand. As a result, the efficiency of HRSG is distinct with respect to the rated value, affecting the entire operation performance. For the purpose of simplification, the thermal performance of HRSG is characterized by the relationship between the rated thermal efficiency $\eta_{\mathrm{HRN}}$ and the rated thermal output $Q_{\mathrm{HRN}}$, which are presented as follows [24]:

$$
\begin{gathered}
\frac{\eta_{\mathrm{HR}}^{t}}{\eta_{\mathrm{HRN}}}=K_{7}\left(\frac{Q_{\mathrm{HR}}^{t}}{Q_{\mathrm{HRN}}}\right)^{2}+K_{8}\left(\frac{Q_{\mathrm{HR}}^{t}}{Q_{\mathrm{HRN}}}\right)+K_{9} \\
Q_{\mathrm{HR}}^{t}=Q_{\mathrm{GT}}^{t} \eta_{\mathrm{HR}}^{t}
\end{gathered}
$$

where $Q_{\mathrm{HR}}^{t}$ refers to the heat generated by HRSG at time $t$ and $\eta_{\mathrm{HR}}^{t}$ denotes the thermal efficiency of HRSG at time $t$, expressed by a quadratic polynomial. $\eta_{\text {HRN }}$ is the rated thermal efficiency of HRSG. $K_{7}$ to $K_{9}$ are fitting constants.

\subsubsection{Gas Boiler}

During the shutdown periods of GT, the gas boiler is used for heating water in this study. Similar to HRSG, the thermal performances of GB are expressed by the relationship between the rated thermal efficiency $\eta_{\mathrm{GBN}}$ and the rated thermal output $Q_{\mathrm{GBN}}$, as well, which are shown as follows:

$$
\begin{gathered}
\frac{\eta_{\mathrm{GB}}^{t}}{\eta_{\mathrm{GBN}}}=K_{10}\left(\frac{Q_{\mathrm{GB}}^{t}}{Q_{\mathrm{GBN}}}\right)^{2}+K_{11}\left(\frac{Q_{\mathrm{GB}}^{t}}{Q_{\mathrm{GBN}}}\right)+K_{12} \\
Q_{\mathrm{GB}}^{t}=\eta_{\mathrm{GB}}^{t} V_{\mathrm{GB}}^{t} \mathrm{LHV}
\end{gathered}
$$

where $Q_{\mathrm{GB}}^{t}$ refers to the heat production of GB at time $t$. $\eta_{\mathrm{GB}}^{t}$ represents the thermal efficiency of $\mathrm{GB}$, while $\eta_{\mathrm{GBN}}$ is the subscript for its nominal parameter. $V_{\mathrm{GB}}^{t}$ denotes the gas consumption of GB at time t. $K_{10}-K_{12}$ are fitting constants.

\subsubsection{Absorption Chiller}

The absorption chiller is a great choice for utilizing the low-grade heat of the waste heat. So far, there are two kinds of chillers for supplying the cooling demand, including the single-effect chiller and double-effect chiller. The double-effect chiller is more widely used due to its higher coefficient of performance compared to the single-effect chiller [26]. Concerning the part-load characteristics of AC, the thermal performance of AC are described as follows [23]:

$$
\frac{\mathrm{COP}_{\mathrm{AC}}^{t}}{\mathrm{COP}_{\mathrm{ACN}}}=\frac{\frac{Q_{\mathrm{AC}}^{t}}{Q_{\mathrm{ACN}}}}{K_{13}\left(\frac{Q_{\mathrm{AC}}^{t}}{Q_{\mathrm{ACN}}}\right)^{3}+K_{14}\left(\frac{Q_{\mathrm{AC}}^{t}}{Q_{\mathrm{ACN}}}\right)^{2}+K_{15}\left(\frac{Q_{\mathrm{AC}}^{t}}{Q_{\mathrm{ACN}}}\right)+K_{16}}
$$




$$
Q_{\mathrm{AC}}^{t}=\mathrm{COP}_{\mathrm{AC}}^{t} Q_{\mathrm{ACin}}^{t}
$$

where $Q_{\mathrm{AC}}^{t}$ is the cooling energy output of $\mathrm{AC}$ and $\mathrm{ACN}$ is the subscript for its nominal parameter. $\mathrm{COP}_{\mathrm{AC}}^{t}$ refers to the coefficient of performance of $\mathrm{AC}$ at time $t . Q_{\mathrm{AC} \text { in }}^{t}$ denotes the steam heat consumed by AC at time $t$.

\subsubsection{Electric Chiller}

The electric chiller generates cooling through consuming high quality electricity so that the coefficient of performance of EC is higher than that of AC. Taking the part-load characteristics of EC into consideration, the thermal performance of EC is expressed as [23]:

$$
\begin{gathered}
\frac{\mathrm{COP}_{\mathrm{EC}}^{t}}{\mathrm{COP}_{\mathrm{ECN}}}=\frac{\frac{Q_{\mathrm{EC}}^{t}}{Q_{\mathrm{ECN}}}}{K_{17}\left(\frac{Q_{\mathrm{EC}}^{t}}{Q_{\mathrm{ECN}}}\right)^{2}+K_{18}\left(\frac{Q_{\mathrm{EC}}^{t}}{Q_{\mathrm{ECN}}}\right)+K_{19}} \\
Q_{\mathrm{EC}}^{t}=\mathrm{COP}_{\mathrm{EC}}^{t} P_{\mathrm{EC}}^{t}
\end{gathered}
$$

where $Q_{\mathrm{EC}}^{t}$ is the cooling energy output of EC. $\mathrm{COP}_{\mathrm{EC}}^{\mathrm{t}}$ refers to the coefficient of performance of $\mathrm{EC}$ at time t. $P_{\mathrm{EC}}^{t}$ denotes the power consumed by EC at time $t$.

\subsubsection{Heat Exchanger}

In view of the fact that the thermal efficiency of the heat exchanger is almost the same under various heating load conditions, a fixed thermal efficiency of HE is given by:

$$
\eta_{\mathrm{HE}}^{t}=\eta_{\mathrm{HEN}}=\frac{Q_{\mathrm{HEout}}^{t}}{Q_{\mathrm{HEin}}^{t}}
$$

where $\eta_{\mathrm{HE}}^{t}$ represents the thermal efficiency of HE. $Q_{\mathrm{HEin}}^{t}$ and $Q_{\mathrm{HEout}}^{t}$ are the heat input and output of HE at time $t$, respectively.

\subsection{Simplified Model}

In this subsection, the simplified model of the EH is also presented. In the simplified model, the efficiencies of generation units are treated as constants, which are shown as follows:

$$
\begin{aligned}
\eta_{\mathrm{GTe}}^{t} & =\eta_{\mathrm{GTeN}} \\
\eta_{\mathrm{GTh}}^{t} & =\eta_{\mathrm{GThN}} \\
\eta_{\mathrm{HR}}^{t} & =\eta_{\mathrm{HRN}} \\
\eta_{\mathrm{GB}}^{t} & =\eta_{\mathrm{GBN}} \\
\mathrm{COP}_{\mathrm{AC}}^{\mathrm{t}} & =\mathrm{COP}_{\mathrm{ACN}} \\
\mathrm{COP}_{\mathrm{EC}}^{\mathrm{t}} & =\mathrm{COP}_{\mathrm{ECN}}
\end{aligned}
$$

where $\eta_{\mathrm{GT}}^{t} \eta_{\mathrm{GTh}}^{t}$ refer to the the electrical and thermal efficiency of GT at time $t$, respectively. $\eta_{\mathrm{GTNN}}, \eta_{\mathrm{GThN}}, \eta_{\mathrm{HRN}}, \eta_{\mathrm{GBN}}, \mathrm{COP}_{\mathrm{ACN}}$ and $\mathrm{COP}_{\mathrm{ECN}}$ are the rated efficiency of GT, HR, GB, AC and EC, respectively. 


\section{The Optimal Capacity Configuration Problem Formulation}

\subsection{Decision Variables}

As the optimal capacity configuration problem consists of the design and operation stages, the decision variables of this sizing problem are divided into design variables and operation variables. As we have considered the running state of each generation unit, the operation variables consist of continuous operational variables and binary operation variables. The design variables are the capacities of GT, HRSG, GB, AC, EC and HE, which are formulated as follows:

$$
d=\left[P_{\mathrm{GT}}^{\text {rated }}, P_{\mathrm{HRSG}}^{\text {rated }}, P_{\mathrm{GB}}^{\text {rated }}, P_{\mathrm{AC}}^{\text {rated }}, P_{\mathrm{EC}}^{\text {rated }}, P_{\mathrm{HE}}^{\text {rated }}\right]^{\mathrm{T}}
$$

where $d$ is a vector of continuous design variables, representing the capacities of generation units.

The continuous operation variables are presented as:

$$
x^{t}=\left[P_{\text {pur }}^{t}, P_{\text {sold }}^{t}, V_{\mathrm{GT}}^{t}, V_{\mathrm{GB}}^{t}, P_{\mathrm{EC}}^{t}, Q_{\mathrm{ACin}}^{t}\right]^{\mathrm{T}}
$$

where $x^{t}$ denotes a vector of continuous operational variables, consisting of the power purchased from the grid $P_{\text {pur }}^{t}$, power sold to the grid $P_{\text {sold }}^{t}$, gas consumption of GT $V_{\mathrm{GT}}^{t}$ and GB $V_{\mathrm{GB}}^{t}$, power consumed by EC $P_{\mathrm{EC}}^{t}$ and the energy input of $\mathrm{AC} Q_{\mathrm{AC} \text { in }}^{t}$ at time $t$.

Taking the on-off state of generation units into consideration, the binary variables are given by:

$$
b^{t}=\left[\delta_{\mathrm{GT}}^{t}, \delta_{\mathrm{HR}}^{t}, \delta_{\mathrm{GB}}^{t}, \delta_{\mathrm{AC}}^{t}, \delta_{\mathrm{EC}}^{t}\right]^{\mathrm{T}}
$$

where $b^{t}$ is a vector of binary operation variables, indicating the running state of each generation unit.

\subsection{Objective Function}

The capacity configuration problem aims at finding the optimal sizes for the generation units in the $\mathrm{EH}$ to achieve the best economic benefits at the same time. As for the economic indicators, life cycle cost is often used to evaluate the economic feasibility of a project [27]. In this paper, the life cycle cost of an EH is chosen as the objective function to be minimized. As shown in Equation (16), the objective function is composed of three parts, including capital cost, residual cost and operation and maintenance $(\mathrm{O} \& \mathrm{M})$ cost.

$$
C_{\text {total }}=C_{\text {cap }}+C_{\mathrm{rc}}+C_{\mathrm{O \&} \mathrm{M}}
$$

where $C_{\text {total }}$ is the life cycle cost of the EH. $C_{\text {cap }}$ refers to the capital cost. $C_{\mathrm{rc}}$ denotes the residual cost of the generation units of the $\mathrm{EH}$. $\mathrm{C}_{\mathrm{O} \& \mathrm{M}}$ stands for the operation and maintenance $(\mathrm{O} \& \mathrm{M})$ cost.

The capital cost corresponds to the cost of buying the equipment, which is given by:

$$
C_{\text {cap }}=\sum_{i=1}^{I}\left\{\left(1+c_{i}^{\text {ins }}\right) c_{i}^{\text {cap }} P_{i}^{\text {rated }}+F_{i}^{\text {cap }}\right\}
$$

where $I$ is the number of generation units. As the capital cost is composed of a variable one and fixed one, $c_{i}^{\text {cap }}$ denotes the per-unit variable initial investment cost of equipment $i$, while $F_{i}^{\text {cap }}$ stands for the fixed capital cost of equipment $i . c_{i}^{\text {ins }}$ represents the installation cost coefficient of the $i$-th unit, which is taken as a fraction of its initial investment cost. $P_{i}^{\text {rated }}$ denotes the rated capacity of the $i$-th unit.

The operation and maintenance cost is paid to maintain the yearly operation and maintenance of the $\mathrm{EH}$, which is given by:

$$
C_{\mathrm{O} \& \mathrm{M}}=\sum_{n=1}^{N}\left(C_{n}^{\mathrm{mnt}}+C_{n}^{\mathrm{em}}+C_{n}^{\mathrm{op}}\right) D(r, n)
$$


where $N$ is the expected life span of the EH. $C_{n}^{\mathrm{mnt}}, C_{n}^{\mathrm{em}}$ and $C_{n}^{\mathrm{op}}$ are the maintenance cost, the emission cost and the operation cost of the $n$-th year, respectively. $D(r, n)$ denotes the present worth factor of the $n$-th year, which is represented as follows:

$$
D(r, n)=(1+r)^{-n}
$$

where $r$ is the real interest rate.

Similar to the capital cost, the maintenance cost contains variable and fixed ones, as well, which is expressed as:

$$
C_{n}^{\mathrm{mnt}}=\sum_{t=1}^{T} \sum_{i=1}^{I}\left(c_{i}^{\mathrm{mf}} P_{i}^{\mathrm{rated}}+c_{i}^{\mathrm{mv}} P_{i}^{t}\right)
$$

where $T$ stands for the total yearly operation hours. $c_{i}^{\mathrm{mf}}$ and $c_{i}^{\mathrm{mv}}$ are per-unit fixed and variable maintenance cost of the $i$-th unit. $P_{i}^{t}$ denotes the amount of the power output at time $t$ of the $i$-th unit.

The environmental quality reduction is mainly caused by the emissions including $\mathrm{CO}, \mathrm{CO}_{2}, \mathrm{SO}_{2}$ and $\mathrm{NO}_{x}$ from utility electricity and natural gas consumption. Due to the fact that the comprehensive utilization of primary energy would make significant progress in reducing pollutant emissions, the emission cost is taken into consideration in this paper. The emission cost can be calculated as follows:

$$
C_{n}^{\mathrm{em}}=\sum_{t=1}^{T} \sum_{j=1}^{J} c^{j}\left(a_{\mathrm{E}}^{j} P_{\mathrm{E}}^{t}+a_{\mathrm{NG}}^{j} P_{\mathrm{NG}}^{t}\right)
$$

where $J$ is the type of pollutant emission. $c^{j}$ refers to the environment value of the $j$-th pollutant emitted. $a_{\mathrm{e}}^{j}$ and $a_{\mathrm{g}}^{j}$ are the per-unit amount of $j$ pollutants caused by the consumption of electricity and natural gas, respectively.

The natural gas cost in each period time $t$ for the EH is expressed as the natural gas utilized multiplied by the price of natural gas, where the natural gas utilized includes the quantity of gas consumed by GT and GB during time $t$. As for the electricity cost, it is worth noting that the redundant electricity can be sold back to the electric grid. Therefore, the electricity cost in each period $t$ consists of the cost of purchasing electricity and the revenue due to the electricity sold back to the grid. The unit price for selling and purchasing electricity is assumed to be the same in this paper. The operation cost $C_{\mathrm{op}}$ is the sum of natural gas and electricity costs, which can be expressed as:

$$
C_{n}^{\mathrm{op}}=\sum_{t=1}^{T}\left\{3600 C_{\mathrm{GT}}\left(V_{\mathrm{GT}}^{t}+V_{\mathrm{GB}}^{t}\right)+C_{\mathrm{E}}^{t}\left(P_{\text {pur }}^{t}-P_{\text {sold }}^{t}\right)\right\}
$$

where $C_{\mathrm{NG}}$ and $C_{\mathrm{E}}^{t}$ are the natural gas price and electricity price, respectively. $P_{\text {pur }}^{t}$ and $P_{\text {sold }}^{t}$ denote the power purchased and sold to the grid at time $t$, respectively.

The residual cost consists of the decommission cost and the salvage value of the equipment, implying the value of all the generation units at the end of the lifespan [3]. The decommission cost and the salvage value of the equipment are presented as follows:

$$
\begin{gathered}
C_{\mathrm{rc}}=\sum_{i=1}^{I}\left(C_{i}^{\mathrm{dc}}-C_{i}^{\mathrm{sc}}\right) D(r, N) \\
C_{i}^{\mathrm{dc}}=c_{i}^{\mathrm{dc}} c_{i}^{\mathrm{cap}} P_{i}^{\text {rated }} \\
C_{i}^{\mathrm{sc}}=c_{i}^{\mathrm{sc}} c_{i}^{\mathrm{cap}} P_{i}^{\text {rated }}
\end{gathered}
$$

where $C_{i}^{\mathrm{dc}}$ and $C_{i}^{\mathrm{sc}}$ refer to the decommission cost and salvage value of the $i$-th energy generation unit, respectively. $c_{i}^{\mathrm{dc}}$ and $c_{i}^{\mathrm{sc}}$ denote the fraction of decommission cost and salvage value to the initial expenditure of the $i$-th energy generation unit, respectively. 


\subsection{Constraints}

In the optimal capacity configuration problem of the $\mathrm{EH}$, the constraints consist of capacity constraints, the energy balance constraints and various generation units' performance constraints, which are presented in the following.

\subsubsection{Capacity Constraints}

The lower and upper bounds of the capacity of each generation unit should be limited in order to avoid the profligacy of resources.

$$
P_{i}^{\min } \leq P_{i}^{\text {rated }} \leq P_{i}^{\max }
$$

where $P_{i}^{\min }, P_{i}^{\max }$ and $P_{i}^{\text {rated }}$ refer to the minimum, maximum and rated capacity of $i$-th energy equipment, respectively.

\subsubsection{Energy Balance Relationships}

Electricity balance at time $t$ in the $\mathrm{EH}$ can be expressed as:

$$
P_{\mathrm{GT}}^{t}+P_{\mathrm{pur}}^{t}-P_{\mathrm{EC}}^{t}-P_{\mathrm{sold}}^{t}=L_{\mathrm{E}}^{t}
$$

where $L_{\mathrm{E}}^{t}$ denotes the electricity load.

The thermal load balance is formulated as:

$$
Q_{\mathrm{HEout}}^{t} \geq L_{\mathrm{H}}^{t}
$$

where $L_{\mathrm{H}}^{t}$ denotes the heating load.

The cooling load balance is defined as:

$$
Q_{\mathrm{EC}}^{t}+Q_{\mathrm{AC}}^{t} \geq L_{\mathrm{C}}^{t}
$$

where $L_{C}^{t}$ denotes the cooling load.

It can be observed from Equations (34) and (35) that there exist two situations in the cooling and heat production. One of the situations is that the energy generated is greater than the demand, and the other one is that the energy generated is just equal to the demand. The two different operation strategies mentioned above correspond to two kinds of operation strategies for the EH, including profit-oriented operation mode and heat load following mode. The operation modes will be covered in more depth in Section 4.

\subsubsection{Generation Units' Performance Constraints}

The output of each equipment in the EH has to be set between its minimum and maximum values. Moreover, in order to consider the on-off status of each device, the operational limits of generation units can be expressed by:

$$
\begin{aligned}
& \delta_{\mathrm{GT}}^{t} \alpha_{\mathrm{GT}} P_{\mathrm{GT}}^{\text {rated }} \leq P_{\mathrm{GT}}^{t} \leq \delta_{\mathrm{GT}}^{t} P_{\mathrm{GT}}^{\text {rated }}, \delta_{\mathrm{GT}}^{t} \in\{0,1\} \\
& \delta_{\mathrm{HR}}^{t} \alpha_{\mathrm{HR}} Q_{\mathrm{HR}}^{\text {rated }} \leq Q_{\mathrm{HR}}^{t} \leq \delta_{\mathrm{HR}}^{t} Q_{\mathrm{HR}}^{\text {rated }}, \delta_{\mathrm{HR}}^{t} \in\{0,1\} \\
& \delta_{\mathrm{GB}}^{t} \alpha_{\mathrm{GB}} Q_{\mathrm{GB}}^{\text {rated }} \leq Q_{\mathrm{GB}}^{t} \leq \delta_{\mathrm{GB}}^{t} Q_{\mathrm{GB}}^{\text {rated }}, \delta_{\mathrm{GB}}^{t} \in\{0,1\} \\
& \delta_{\mathrm{EC}}^{t} \alpha_{\mathrm{EC}} Q_{\mathrm{EC}}^{\text {rated }} \leq Q_{\mathrm{EC}}^{t} \leq \delta_{\mathrm{EC}}^{t} Q_{\mathrm{EC}}^{\text {rated }}, \delta_{\mathrm{EC}}^{t} \in\{0,1\} \\
& \delta_{\mathrm{AC}}^{t} \alpha_{\mathrm{AC}} Q_{\mathrm{AC}}^{\text {rated }} \leq Q_{\mathrm{AC}}^{t} \leq \delta_{\mathrm{AC}}^{t} Q_{\mathrm{AC}}^{\text {rated }}, \delta_{\mathrm{AC}}^{t} \in\{0,1\}
\end{aligned}
$$




\subsubsection{Opposite Conditions}

Due to the fact that the selling and purchasing of electricity cannot be conducted simultaneously, $P_{\text {pur }}^{t}$ and $P_{\text {sold }}^{t}$ have the relationship described as follows:

$$
P_{\text {pur }}^{t} P_{\text {sold }}^{t}=0, P_{\text {pur }}^{t} \geq 0, P_{\text {sold }}^{t} \geq 0
$$

\subsection{Solution Method}

As shown in Figure 2, a two-stage optimization method is proposed to solve the EH capacity configuration problem. In the first stage, GSO is used to obtain the optimal capacity configurations of the EH. GSO is a population-based optimization algorithm. The group consists of three kinds of members: the producer, scroungers and rangers. The member who has the best fitness value is selected as the producer, and it always searches for better resources by sampling three positions randomly in the scanning field. Scroungers take up a large percent of GSO members, and they keep searching for opportunities to locate the resources founded by the producer, which means scroungers move towards and search in the small area around the producer. Besides the producer and scroungers, the rest of the members are called rangers, which walk randomly to locate resources efficiently and escape from the local optima. Due to the large size of the optimization problem in this study, GSO is considered to be a suitable approach. A detailed introduction to the behaviours of producer, scrounger and ranger can be found in Ref. [28].

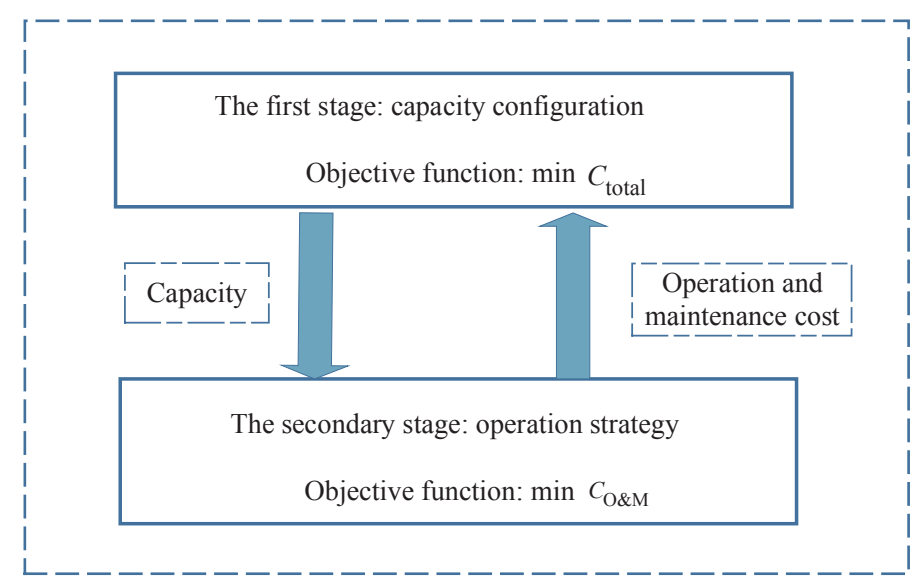

Figure 2. Diagram of the two-stage optimal method.

The MINLP method is used to solve the problem of the second stage. A complete MINLP problem consists of an objective function for the maximum or minimum value, optimization variables and constraints. In this paper, Equation (18) is the objective function; Equations (1)-(12), (24)-(28), and (33) are equality constraints; Equations (34) and (35) are inequality constraints; Equations (36)-(40) are lower and upper bound constraints.

Firstly, given the values $P_{\mathrm{GT}}^{\text {rated }}, P_{\mathrm{HRSG}}^{\text {rated }}, P_{\mathrm{GB}}^{\text {rated }}, P_{\mathrm{AC}}^{\text {rated }}, P_{\mathrm{EC}}^{\text {rated }}$ and $P_{\mathrm{HE}}^{\text {rated }}$ obtained from the first stage, the optimal operation strategy of the second stage can be obtained. Afterwards, based on the operation results of the second stage, the optimal value that minimizes the total cost will be found by GSO. Based 
on these analyses, the two-stage programming problem can be formulated as a master problem in combination with a sub-problem, which is shown as follows:

$$
\begin{aligned}
\text { (Master) }: & \min C_{\mathrm{total}}\left(b_{t \in T}^{*}, x_{t \in T}^{*}, d\right) \\
\text { s.t. } & G\left(b_{t \in T}^{*}, x_{t \in T}^{*}, d\right)=0 \\
& H\left(b_{t \in T}^{*}, x_{t \in T}^{*}, d\right) \leq 0 \\
(\text { Sub }): & \min C_{\mathrm{O} \& \mathrm{M}}\left(b_{t \in T}, x_{t \in T}, d^{*}\right) \\
\text { s.t. } & g\left(b_{t \in T}, x_{t \in T}, d^{*}\right)=0 \\
& h\left(b_{t \in T}, x_{t \in T}, d^{*}\right) \leq 0
\end{aligned}
$$

where $C_{\text {total }}$ denotes the objective function at the design stage and $C_{\mathrm{O} \& \mathrm{M}}$ refers to the objective function at the operation stage. $d$ and $x_{t}$ denote the vectors of design and operation variables. $b_{t}$ refers to the binary variables, which are valued as either zero or one. $G$ and $H$ represent the equality and inequality constraints of the design stage, respectively. Similarly, $g$ and $h$ refer to the equality and inequality constraints of the operation stage. Moreover, the superscript ${ }^{* \prime \prime}$ represents the known value at the corresponding optimization stage.

The flowchart of the two-stage optimization method is shown in Figure 3, and the detailed procedures are illustrated as follows.

- Step 1: Initialization. Input the EH data, such as the technical and economic parameters of generation units, electricity, heating and cooling demand and natural gas price. Then, initialize all of the group members $M$ and the total number of iterations $N$ of GSO.

- $\quad$ Step 2: GSO solution update.

a. Each of the group member is used with the second stage problem. The MINLP optimization is run.

b. The GSO fitness function value is then computed to determine the total cost of each group member.

c. The process continues until the number of group members reaches $M$. Then, GSO generates new members.

- $\quad$ Step 3: Stopping criterion. If the maximum number of iterations reaches $N$, the execution stops. Otherwise, it continues from Step 2.

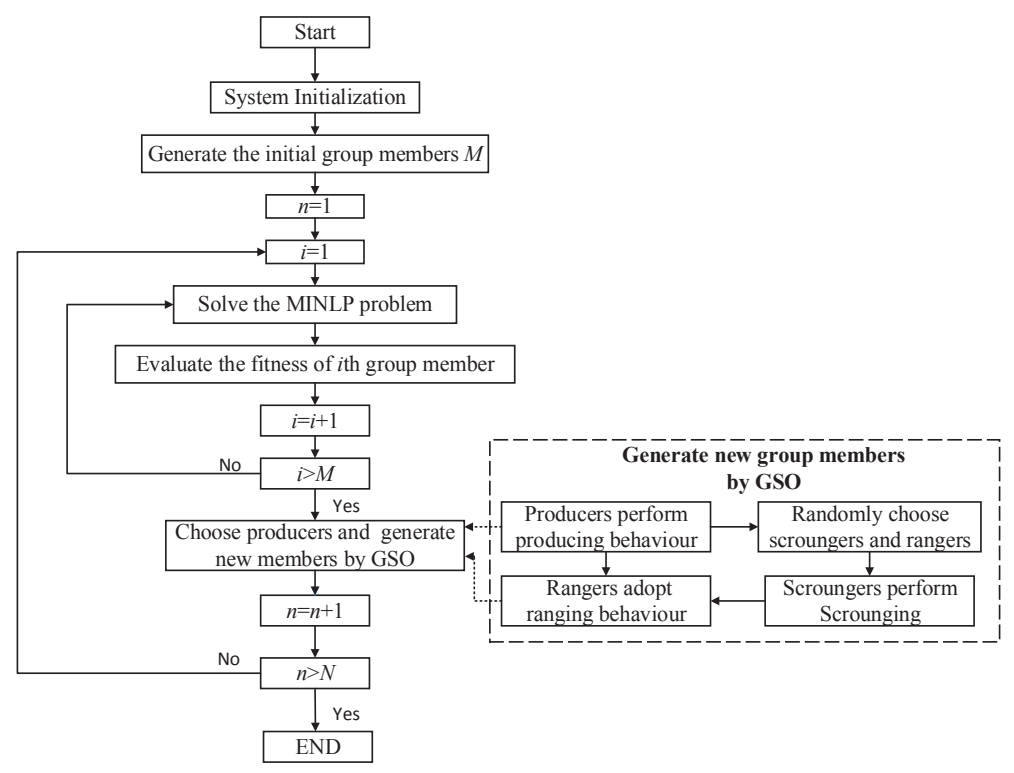

Figure 3. Optimization process outline. 


\section{Case Study}

With the optimization method and its solution strategy described in Section 3, the PLCB model and the simplified model proposed in Section 2 are applied to the design of the EH for a hotel in Beijing. Two cases are investigated for comparison purpose. In Case 1, the PLCB and simplified models of the $\mathrm{EH}$ are operated with profit-oriented mode. In this mode, the heating and cooling energies produced by generation units are allowed to be larger than the demand. In Case 2, the two proposed models are operated with the thermal load following operation strategy. In such an operating mode, there is no excess heating and cooling produced, but the surplus electricity is still allowed to be sold back to the outside grid.

To reduce the total number of variables in the optimization model, three types of typical days per year, namely summer, winter and mid-season days, are introduced in consideration of the hotel's seasonal and daily variations in energy demands. Each typical days is divided into three time periods, each of which has eight hours. The definition of typical days are shown in Table 1. Table 2 shows the energy prices, as well as the energy demands during the peak, even and low periods. It can be observed that the electricity price varies with time, while the price of natural gas is kept as $0.45 \$ / \mathrm{m}^{3}$ in this paper [29]. In addition, it should be mentioned that according to the human thermal comfort study [30], the peak heating load of the consumer usually occurs when the electricity price is low, while the low heating load occurs when the electricity price is even.

Table 1. Definition of typical days.

\begin{tabular}{ccc}
\hline Typical Day & Month & Duration (d/y) \\
\hline Summer & June-August & 91 \\
Winter & November, December, January & 91 \\
Mid-season & February-May, September-October & 183 \\
\hline
\end{tabular}

Table 2. Demand and energy price during peak, even and low periods.

\begin{tabular}{ccccc}
\hline \multicolumn{2}{c}{ Item } & Peak Hours & Even Hours & Low Hours \\
\hline \multicolumn{2}{c}{ Electricity Tariff $(\$ / \mathrm{kWh})$} & 0.133 & 0.079 & 0.027 \\
\multicolumn{2}{c}{ Natural Gas Price $\left(\$ / \mathrm{m}^{3}\right)$} & 0.45 & 0.45 & 0.45 \\
\hline \multirow{2}{*}{ Electricity Load } & summer & 2500 & 1800 & 1200 \\
$(\mathrm{~kW})$ & winter & 1800 & 1200 & 700 \\
& mid-season & 2000 & 1500 & 1000 \\
\hline \multirow{2}{*}{ Heating Load } & summer & 250 & 150 & 500 \\
$(\mathrm{~kW})$ & winter & 2000 & 1000 & 3000 \\
& mid-season & 1000 & 500 & 1500 \\
\hline \multirow{2}{*}{ Cooling load } & summer & 3000 & 2500 & 1600 \\
$(\mathrm{~kW})$ & winter & 0 & 0 & 0 \\
& mid-season & 1500 & 600 & 100 \\
\hline
\end{tabular}

All case studies are solved using the MATLAB platform. For the first stage optimization, the population size for GSO is 60 , and the maximum iteration number is 300 . For the second stage, the optimization problem for the PLCB model is an MINLP problem, while it is an MILP problem for the simplified model. Both of the MINLP and MILP problems are solved by Solving Constraint Integer Programs (SCIP), which is capable of efficiently solving linear and nonlinear optimization problems that contain a large number of variables.

Tables 3 and 4 show the information on the generation units, including their economic and technical parameters. The discount rate is set as 0.05 in this study. Based on the information reported in Table 4, the performance curves of the PLCB model based on the Part Load Ratio (PLR) are depicted in Figure 4. It is obvious that the efficiencies of the units are far different from their rated value, implying 
that ignoring the part-load characteristics may lead to inaccurate results for the optimal sizing of EH. In addition, Table 5 shows the pollutant emission factors and the environment values of the electricity and natural gas.

Table 3. The economic parameter settings of the GT, gas turbine; HRSG, heat recovery steam generator; GB, gas boiler; AC, absorption chiller; HE, heat exchanger.

\begin{tabular}{|c|c|c|c|c|}
\hline Generation Units & $\begin{array}{c}\text { Capacity } \\
\text { Independent Cost } \\
(\$)\end{array}$ & $\begin{array}{c}\text { Capacity } \\
\text { Dependent Cost } \\
(\$ / k W)\end{array}$ & $\begin{array}{c}\text { Fixed } \\
\text { Maintenance Cost } \\
(\$ / \mathbf{k W})\end{array}$ & $\begin{array}{c}\text { Variable } \\
\text { Maintenance Cost } \\
(\$ / \mathrm{kWh})\end{array}$ \\
\hline GT & 0 & 1452 & 0 & 0.0078 \\
\hline HRSG & 0 & 42 & 0.037 & 0 \\
\hline GB & 0 & 40 & 0.03 & 0 \\
\hline $\mathrm{AC}$ & 20550.6 & 726 & 0.01 & 0 \\
\hline $\mathrm{EC}$ & 0 & 881 & 0.01 & 0 \\
\hline $\mathrm{HE}$ & 0 & 42 & 0.037 & 0 \\
\hline
\end{tabular}

Table 4. The technical parameter settings of the EH.

\begin{tabular}{|c|c|c|c|}
\hline Unit & Term & Value & Life (Year) \\
\hline GT & $\begin{array}{c}\eta_{\mathrm{GTeN}} \\
\alpha_{\mathrm{GT}}^{\mathrm{min}} \\
K_{1} \\
K_{2} \\
K_{3} \\
K_{4} \\
K_{5} \\
K_{6}\end{array}$ & $\begin{array}{c}0.33 \\
0.05 \\
-0.000004 \\
1.0585 \\
-1448 \\
0.000001 \\
1.7751 \\
1474\end{array}$ & 20 \\
\hline $\mathrm{AC}$ & $\begin{array}{c}\mathrm{COP}_{\mathrm{ACN}} \\
\alpha_{\mathrm{AC}}^{\min } \\
K_{16} \\
K_{17} \\
K_{18} \\
K_{19}\end{array}$ & $\begin{array}{c}1.676 \\
0.05 \\
0.66 \\
-0.915 \\
1.27 \\
0.015\end{array}$ & 20 \\
\hline $\mathrm{HE}$ & $\eta_{\mathrm{HE}}$ & 0.9 & 20 \\
\hline HRSG & $\begin{array}{c}\eta_{\mathrm{HRN}} \\
\alpha_{\mathrm{HR}}^{\min } \\
K_{7} \\
K_{8} \\
K_{9}\end{array}$ & $\begin{array}{c}0.9 \\
0.05 \\
-0.6249 \\
1.525 \\
0.0951\end{array}$ & 20 \\
\hline GB & $\begin{array}{c}\eta_{\mathrm{GBN}} \\
\alpha_{\mathrm{GB}}^{\mathrm{min}} \\
K_{10} \\
K_{11} \\
K_{12} \\
\end{array}$ & $\begin{array}{c}0.9 \\
0.05 \\
-0.6249 \\
1.525 \\
0.0951\end{array}$ & 20 \\
\hline $\mathrm{EC}$ & $\begin{array}{c}\mathrm{COP}_{\mathrm{ECN}} \\
\alpha_{\mathrm{EC}}^{\min } \\
K_{13} \\
K_{14} \\
K_{15}\end{array}$ & $\begin{array}{c}4 \\
0.05 \\
0.75 \\
0.0195 \\
0.213\end{array}$ & 20 \\
\hline
\end{tabular}

Table 5. Pollutant emission coefficient and cost factor.

\begin{tabular}{cccc}
\hline Pollutant & Electricity (g/kWh) & Natural Gas (g/kWh) & Environment Value (\$/kg) \\
\hline $\mathrm{CO}$ & 0.1083 & 0.1702 & 0.145 \\
$\mathrm{CO}_{2}$ & 623 & 184.0829 & 0.004125 \\
$\mathrm{NO}_{\mathrm{x}}$ & 2.88 & 0.6188 & 1.25 \\
$\mathrm{SO}_{2}$ & 6.48 & 0.000928 & 0.875 \\
\hline
\end{tabular}



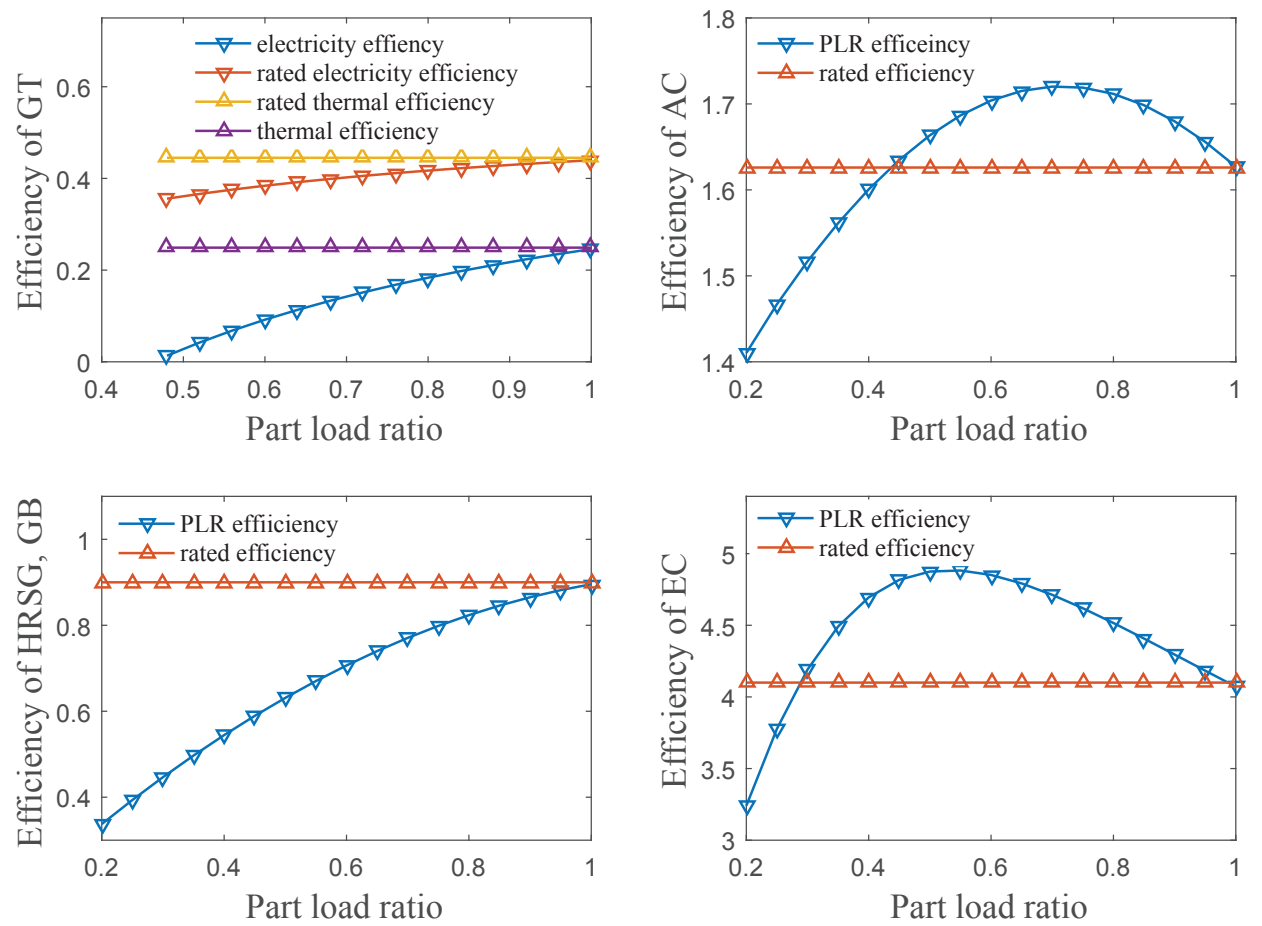

Figure 4. Efficiency curves of GT, AC, EC, GB and HRSG.

\section{Results and Discussions}

\subsection{Optimal Capacity Configuration}

The obtained optimal system capacity configurations of EH for the two cases are shown together in Table 6 for comparison. It can be observed that the sizing results are impacted significantly by the use of different models and operation modes. Focusing on the impacts of the models, results indicate that the capacities of GT and HRSG obtained by the PLCB model are higher than those obtained by the simplified model. This can be explained by the generally lower efficiencies of these units in the PLCB model. Due to the lower efficiencies, for a specified load, the more the amount of power that is needed to supply, the higher the capacity configuration of the units. If inspecting exactly, the capacities of GT and HRSG obtained by the PLCB model in Case 1 are much higher than those in Case 2. It can be also observed from Table 6 that the capacity of GB obtained by the PLCB model is the same as that obtained by the simplified model. In addition, the sizing results obtained by the simplified model in Case 1 is the same as that obtained in Case 2, indicating that the operation mode has no influence on the sizing results for the simplified model.

Table 6. Optimal capacities of generation units for the two cases. EC, electric chiller.

\begin{tabular}{cccccccc}
\hline Operation Mode & EH Model & GT & HRSG & GB & AC & EC & HE \\
\hline \multirow{2}{*}{ Profit-oriented } & Simplified $(\mathrm{kW})$ & 1145 & 2222 & 3333 & 1573 & 1426 & 3000 \\
& Detailed $(\mathrm{kW})$ & 2540 & 4075 & 3333 & 1800 & 1600 & 3104 \\
\hline Thermal load & Simplified $(\mathrm{kW})$ & 1145 & 2222 & 3333 & 1573 & 1426 & 3000 \\
following & Detailed $(\mathrm{kW})$ & 1747 & 2820 & 3333 & 3000 & 100 & 3000 \\
\hline
\end{tabular}

On the other hand, the capacities of AC, EC and HE obtained by the two models are closely related to their operation modes. For example, the capacity of AC calculated by the PLCB model is higher than that calculated by the simplified model in Case 1, while the result is diametrically opposed in Case 2. Furthermore, the capacity of EC in Case 1 is much smaller than that in Case 2, as the installed 
capacity of EC is in competition with the capacity of AC. Concerning the capacity of HE, the result obtained by the PLCB model in Case 1 is $3104 \mathrm{~kW}$, which is a little higher than that obtained by the simplified model, $3000 \mathrm{~kW}$. This is because the heat produced in this case is allowed to be larger than the demand. While in Case 2, as the supply and demand of heat is balanced, the capacities of HE obtained by the two models are just equal to the maximum heating load they faced, which is $3000 \mathrm{~kW}$.

Figure 5 shows the convergence of the objective function of the PLCB and simplified models for the two cases. In addition, the various obtained costs calculated by the two models for Case 1 and Case 2 are also analysed. Firstly, we only take the impact of the models into consideration. Figure 6 shows that the O\&M costs are the highest, and the capital costs and the residual costs remain relatively small both for the PLCB and simplified models. In addition, the PLCB model has a larger capital cost, due to the larger capacity configurations of generation units compared to the simplified model. However, the O\&M cost obtained by the PLCB model is much lower than that obtained by the simplified model, which has the decisive influence on the total cost. Therefore, a $12 \%$ lower life cycle cost of EH with the PLCB model can be observed in Case 1 compared to that with the simplified model, indicating that the model considering the part-load characteristics of generation units has a better economic performance on the optimal capacity configuration of $\mathrm{EH}$.

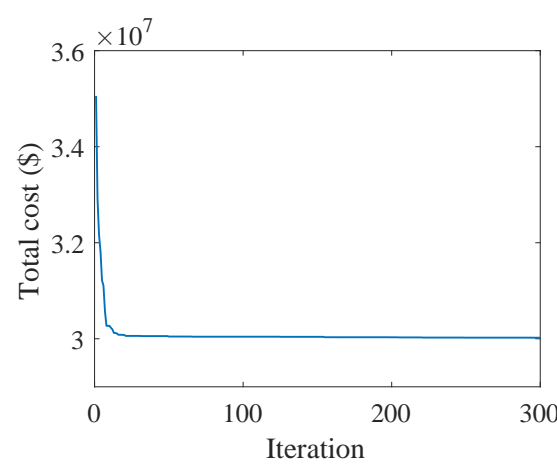

Detailed model

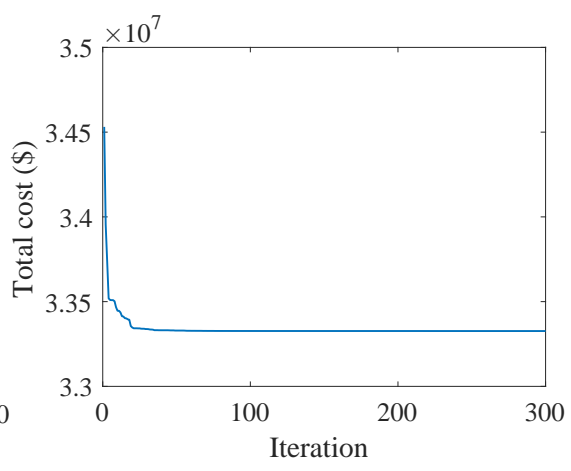

Simplified model

(a) Case 1

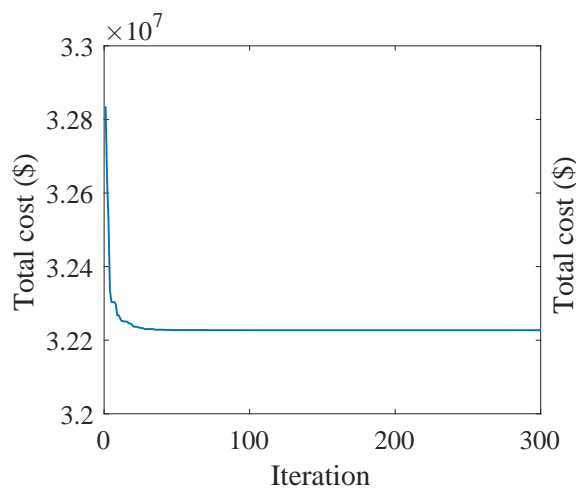

Detailed model

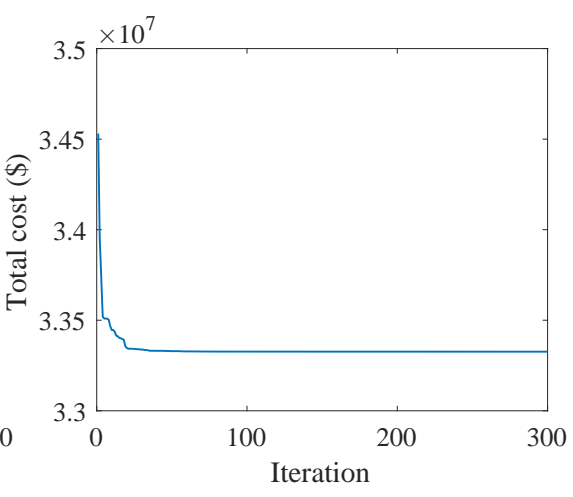

Simplified model

(b) Case 2

Figure 5. Convergence characteristics of the detailed model and the simplified model for the two cases. 


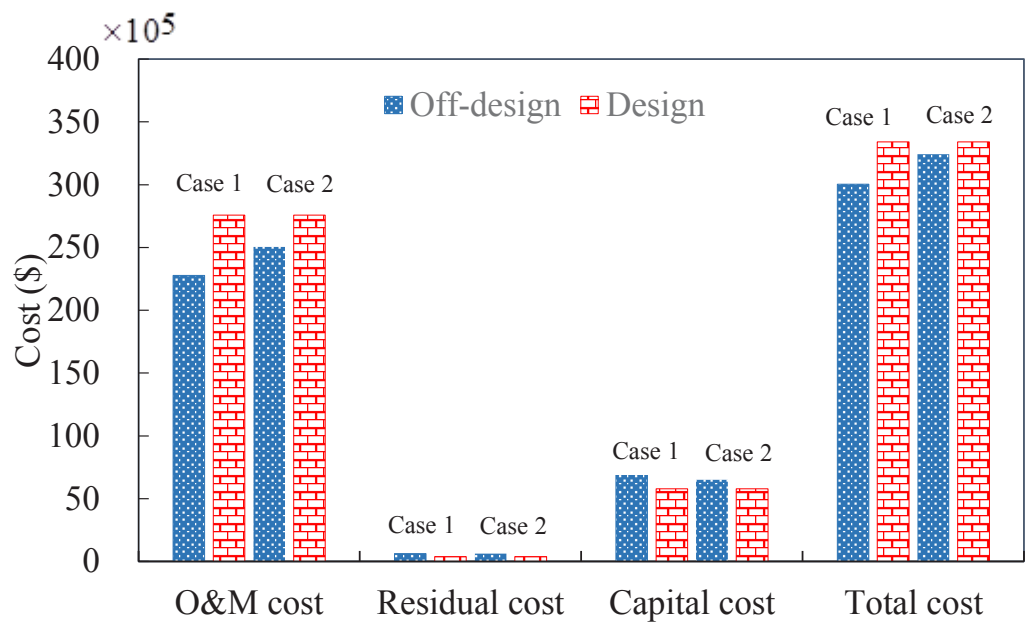

Figure 6. Cost comparison of detailed and simplified models for Case 1 and Case 2.

Then, the impact of the operation mode on the cost will be analysed. As shown in Figure 6, the cost results obtained by the simplified model in Case 1 are the same as those obtained in Case 2 . In terms of the PLCB model, there apparently exist differences between Case 1 and Case 2. It can be observed that the capital cost for Case 1 is 0.7 million dollars, which is bigger than that for Case 2, 0.6 million dollars. Concerning the O\&M cost, it is 2.2 million for Case 1, while it is 2.5 million for Case 2. As the the O\&M cost reduced is larger than capital cost added, the total cost obtained by the PLCB model for Case 1 is finally smaller than that for Case 2 . Therefore, it can be concluded that EH operating with profit-oriented mode is more economic compared to $\mathrm{EH}$ operating with thermal load following mode.

\subsection{Optimal Operation Strategy}

The annual operation strategy of EH calculated by the PLCB and simplified models of Case 1 are graphically represented in Figures 7-9. In addition, the operation results of Case 2 are shown in Figures 10-12.

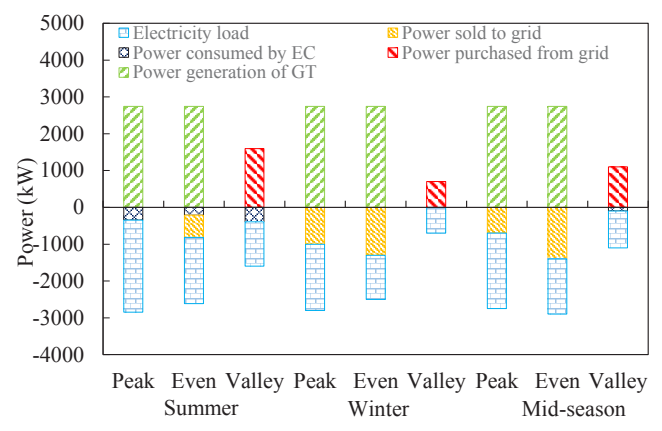

(a) detailed model

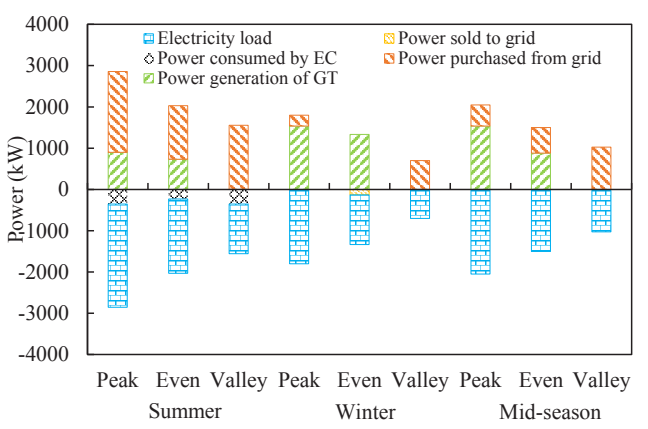

(b) simplified model

Figure 7. Electricity optimization results as for Case 1. 


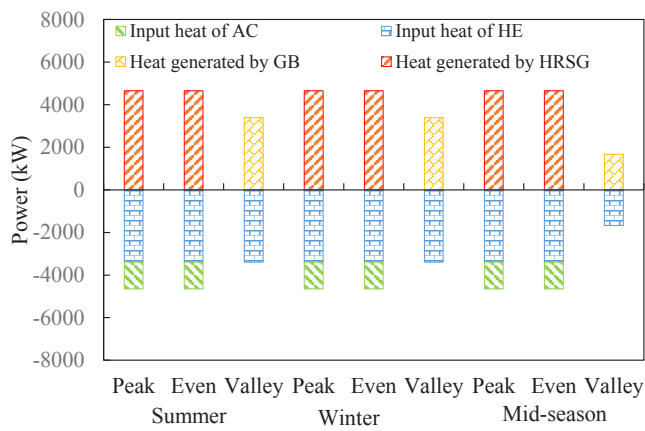

(a) detailed model

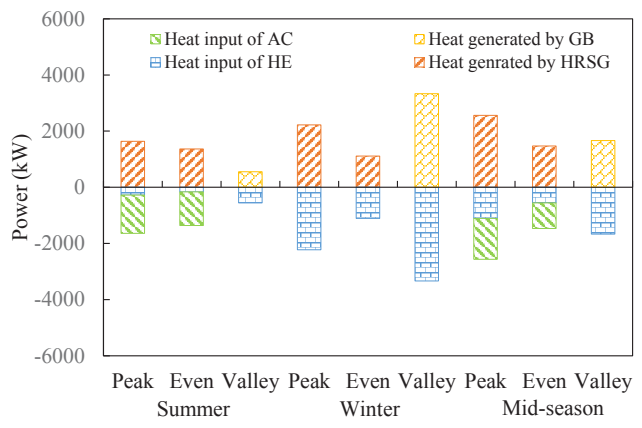

(b) simplified model

Figure 8. Heating optimization results as for Case 1.

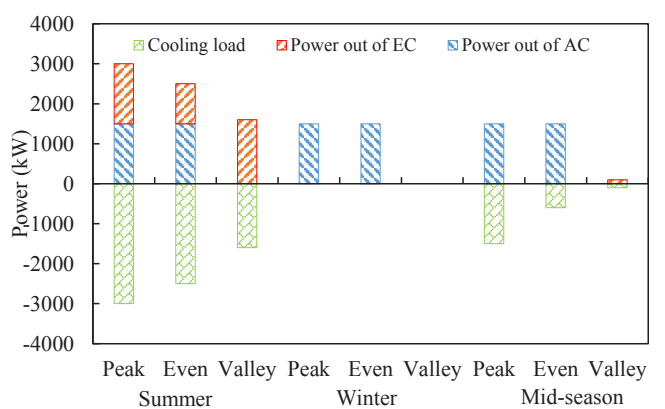

(a) detailed model

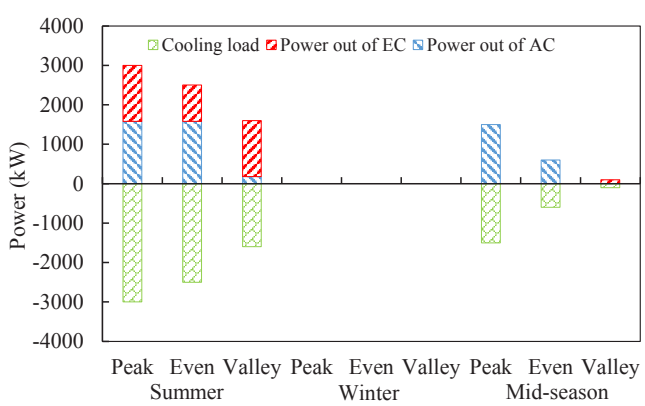

(b) simplified model

Figure 9. Cooling optimization results as for Case 1.

For Case 1, it can be observed from Figure 7 that the optimal dispatch of electricity obtained by the PLCB model and simplified model is quite different. At the peak and even periods during the whole year, GT undertakes all the electricity demand for the PLCB model, while it supplies only part of the electricity demand for the simplified model. The grid supplies the shortfall of electricity if the GT cannot meet the demand. Besides, due to the higher amount of electricity generated by GT, the amount of electricity sold back to the grid of the PLCB model is more than that of the simplified model. If inspecting exactly, the electricity sold back to the grid in winter is relatively higher than that in the summer or mid-season. This is because the electricity used to drive EC in winter is lesser than that in other seasons. In valley periods, the electricity demands are entirely covered by the grid for the two models as the electricity tariff is low.

Figure 8 shows the optimal heating dispatch for the two models. It can be observed that GB is used as the backup-heating source when the waste heat output of GT cannot meet the thermal demand. The excess thermal output of GT is used to drive the absorption chiller to provide cooling demand for the hotel. Concerning the heating output of HRSG during the peak and even periods, a significant increase in the PLCB model can be observed compared to the simplified model. While in valley periods, the HRSGs of both models do not operate, as the GTs of the two models have already stopped running. The heating demand is supplied by GB during the valley periods for both models, and therefore, the same GB capacity of the two models can be obtained as the maximum heating load occurs during the valley periods. Moreover, the heating produced by HE for the PLCB model is much more than that for the design model all year round since the wasting of heat will not be penalized.

The supply and demand for cooling energy are balanced as shown in Figure 9. It can be seen that the same cooling optimal schedules of summer and mid-season days are formulated by the two models. During peak and even periods of the winter days, there is no cooling generated for the simplified model, while the cooling generated by the PLCB model is much more than the demand, resulting in the wasting of cooling energy. In addition, during the peak and even periods, the excess thermal output of 
GT makes AC more competitive compared to using EC. When GT is off during valley periods, EC is a more efficient choice due to the relatively lower investment cost and higher COP compared to AC.

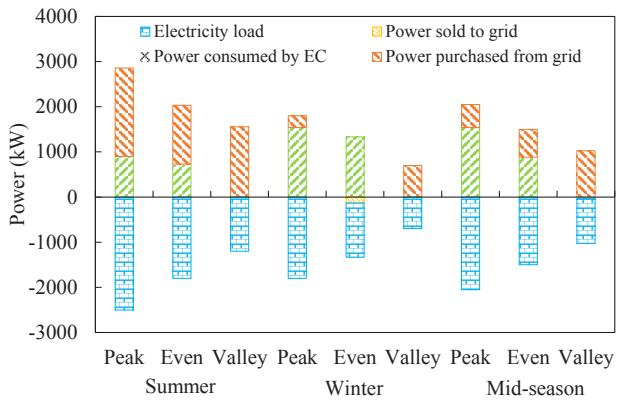

(a) detailed model

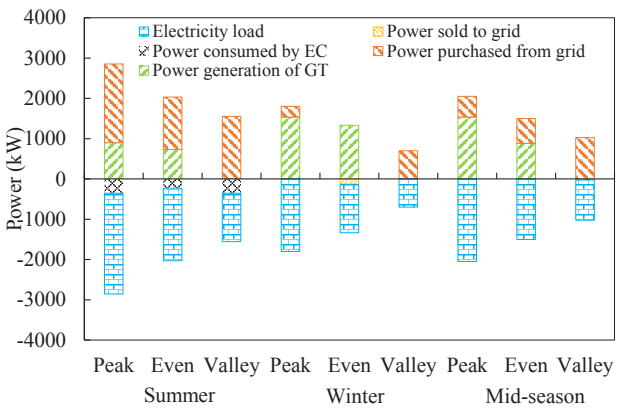

(b) simplified model

Figure 10. Electricity optimization results as for Case 2.

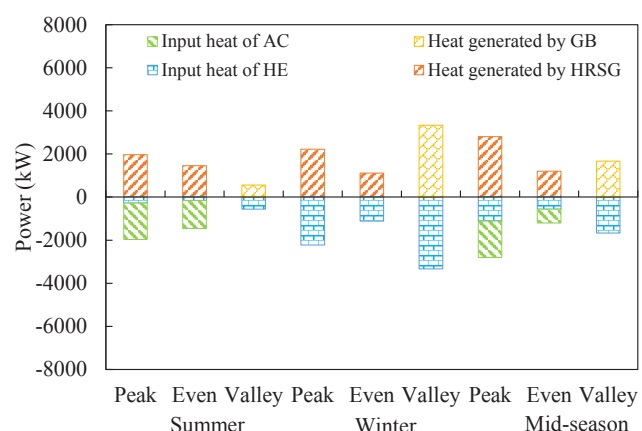

(a) detailed model

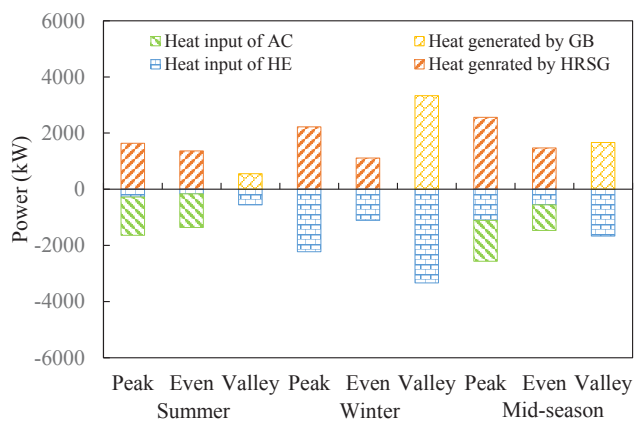

(b) simplified model

Figure 11. Heating optimization results as for Case 2.

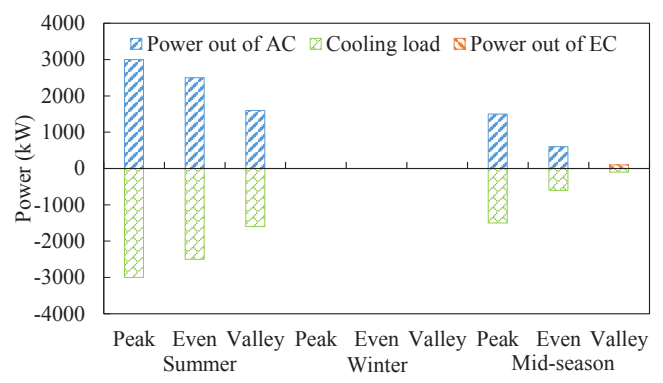

(a) detailed model

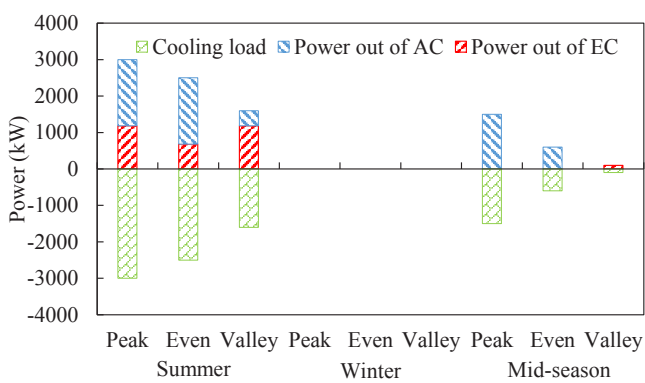

(b) simplified model

Figure 12. Cooling optimization results as for Case 2.

For Case 2, the electricity, heating and cooling optimal schedules obtained by the simplified model are the same as those for Case 1, while the optimal schedules obtained by the PLCB model are a bit different. As shown in Figure 10, the power generated by GT during peak and even periods in this case is much smaller than that in Case 1 as the heat generated is not allowed to be greater than the demand. Similarly, Figure 11 shows that the heat generated by HRSG during peak and even periods is also smaller than that in Case 1. In the rest of the days of the year, the optimal electricity and heating dispatch obtained by the PLCB model are similar to those obtained by the simplified model, which are not repeated here for the sake of conciseness. In terms of the cooling optimal schedules, there apparently exist differences between Case 1 and Case 2. As shown in Figure 12, AC undertakes almost 
all of the cooling load all year in this case, while the cooling demand is largely satisfied by AC with a small remainder supported by EC in Case 1. This is a direct consequence of the much larger capacity configuration of AC in this case compared to the capacity in Case 1.

\section{Conclusions}

In this paper, we have presented a PLCB model for the optimal capacity configuration of an EH. In addition, a two-stage planning method is proposed to solve the sizing problem. Test cases have been carried out on the PLCB model and the simplified model for comparison, and the following results have been verified.

The optimal capacities of GT and HRSG of the PLCB model are rather higher than those of the simplified model for both cases, while the capacities of GB obtained by the two models are the same. Furthermore, the optimal capacities of AC, EC and HE calculated from the two models are closely related to their operation mode.

In terms of the life cycle cost, a 12\% lower life cycle cost of the EH with the PLCB model can be observed compared to that with the simplified model for Case 1, while it decreases to 3\% for Case 2 . Hence, it can be concluded that the PLCB model is preferred for the optimal design of EHs with fluctuating energy demands due to its accuracy and economic effect. Additionally, it can be also noted that profit-oriented operation mode is a much better choice for the operation of EHs than thermal load following mode.

The proposed PLCB model is used for the optimal capacity configuration of an EH in this paper, and the impact of this model on the planning of a large-scale integrated energy system will be further studied in our future work.

Acknowledgments: The project is funded by the State Key Program of National Natural Science Foundation of China (Grant No. 51437006), the Guangdong Innovative Research Team Program (No. 201001N0104744201) and the National Natural Science Foundation of China (Grant No. 51377058).

Author Contributions: Shan Deng proposed the part-load characteristics. Zhaoxia Jing, Lilan Wu, Feng Wei and Qinghua Wu were the advisors of Shan Deng. All authors have read and approved the final manuscript.

Conflicts of Interest: The authors declare no conflict of interest.

\section{References}

1. Jing, Z.X.; Jiang, X.S.; Wu, Q.H.; Tang, W.H.; Hua, B. Modelling and optimal operation of a small-scale integrated energy based district heating and cooling system. Energy 2014, 73, 399-415.

2. Zheng, J.H.; Chen, J.J.; Wu, Q.H.; Jing, Z.X. Multi-objective optimization and decision making for power dispatch of a large-scale integrated energy system with distributed DHCs embedded. Appl. Energy 2015, 154, 369-379.

3. Wei, F.; Wu, Q.H.; Jing, Z.X.; Chen, J.J.; Zhou, X.X. Optimal unit sizing for small-scale integrated energy systems using multi-objective interval optimization and evidential reasoning approach. Energy 2016, 111, 933-946.

4. Yuan, R.; Li, T.; Deng, X.; Ye, J. Optimal day-ahead scheduling of a smart distribution grid considering reactive power capability of distributed generation. Energies 2016, 9, 311.

5. Hussain, A.; Bui, V.H.; Kim, H.M.; Im, Y.H.; Lee, J.Y. Optimal energy management of combined cooling, heat and power in different demand type buildings considering seasonal demand variations. Energies 2017, 10, 789.

6. Geidl, M.; Andersson, G. A modeling and optimization approach for multiple energy carrier power flow. In Proceedings of the 2005 IEEE Russia Power Tech, St. Petersburg, Russia, 27-30 June 2005; Volume 38, pp. 1-7.

7. Geidl, M.; Andersson, G. Optimal Power Flow of Multiple Energy Carriers. IEEE Trans. Power Syst. 2007, 22, 145-155.

8. Maniyali, Y.; Almansoori, A.; Fowler, M. Energy Hub Based on Nuclear Energy and Hydrogen Energy Storage. Ind. Eng. Chem. Res. 2013, 52, 7470-7481. 
9. Nazar, M.S.; Haghifam, M.R. Multiobjective electric distribution system expansion planning using hybrid energy hub concept. Electr. Power Syst. Res. 2009, 79, 899-911.

10. Scala, M.L.; Vaccaro, A.; Zobaa, A.F. A goal programming methodology for multiobjective optimization of distributed energy hubs operation. Appl. Therm. Eng. 2014, 71, 658-666.

11. Kamyab, F.; Bahrami, S. Efficient operation of energy hubs in time-of-use and dynamic pricing electricity markets. Energy 2016, 106, 343-355.

12. Najafi, A.; Falaghi, H.; Contreras, J. Medium-term energy hub management subject to electricity price and wind uncertainty. Appl. Energy 2016, 168, 418-433.

13. Bozchalui, M.C.; Hashmi, S.A.; Hassen, H. Optimal Operation of Residential Energy Hubs in Smart Grids. IEEE Trans. Smart Grid 2012, 3, 1755-1766.

14. Bahrami, S.; Sheikhi, A. From Demand Response in Smart Grid Toward Integrated Demand Response in Smart Energy Hub. IEEE Trans. Smart Grid 2016, 7, 650-658.

15. Rastegar, M.; Fotuhi-Firuzabad, M. Load Management in a Residential Energy Hub with Renewable Distributed Energy Resources. Energy Build. 2015, 107, 234-242.

16. Rastegar, M.; Fotuhi-Firuzabad, M.; Zareipour, H. A Probabilistic Energy Management Scheme for Renewable-Based Residential Energy Hubs. IEEE Trans. Smart Grid 2017, 99, 1-11.

17. Maleki, A.; Askarzadeh, A. Comparative study of artificial intelligence techniques for sizing of a hydrogen-based stand-alone photovoltaic/wind hybrid system. Int. J. Hydrogen Energy 2014, 39, 9973-9984.

18. Kaabeche, A.; Belhamel, M.; Ibtiouen, R. Sizing optimization of grid-independent hybrid photovoltaic/wind power generation system. Energy 2011, 36, 1214-1222.

19. Hong, Y.Y.; Lai, Y.M.; Chang, Y.R.; Lee, Y.D.; Liu, P.W.; Sciubba, E. Optimizing capacities of distributed generation and energy storage in a small autonomous power system considering uncertainty in renewables. Energies 2015, 8, 2473-2492.

20. Gamou, S.; Yokoyama, R.; Ito, K. Optimal unit sizing of cogeneration systems under the toleration for shortage of energy supply. Int. J. Energy Res. 2015, 24, 61-75.

21. Rong, A.; Lahdelma, R. An efficient linear programming model and optimization algorithm for trigeneration. Appl. Energy 2005, 82, 40-63.

22. Lozano, M.A.; Carvalho, M.; Serra, L.M. Operational strategy and marginal costs in simple trigeneration systems. Energy 2009, 34, 2001-2008.

23. Li, H.; Nalim, R.; Haldi, P.A. Thermal-economic optimization of a distributed multi-generation energy system-A case study of Beijing. Appl. Therm. Eng. 2006, 26, 709-719.

24. Li, H.; Haldi, P.A.; Favre, P.P. Evaluation of a distributed energy system combined with heating, cooling and power generation through multi-criteria optimization. In Proceedings of the ASME 2003 International Mechanical Engineering Congress and Exposition, Washington, DC, USA, 15-21 November 2003; pp. 277-284.

25. Liu, B.T.; Chien, K.H.; Wang, C.C. Effect of working fluids on organic Rankine cycle for waste heat recovery. Energy 2004, 29, 1207-1217.

26. Shirazi, A.; Taylor, R.A.; White, S.D. A systematic parametric study and feasibility assessment of solar-assisted single-effect, double-effect, and triple-effect absorption chillers for heating and cooling applications. Energy Convers. Manag. 2016, 114, 258-277.

27. Abbes, D.; Martinez, A.; Champenois, G. Life cycle cost, embodied energy and loss of power supply probability for the optimal design of hybrid power systems. Math. Comput. Simul. 2014, 98, 46-62.

28. He, S.; Wu, Q.H.; Saunders, J.R. Group Search Optimizer: An Optimization Algorithm Inspired by Animal Searching Behavior. IEEE Trans. Evolut. Comput. 2009, 13, 973-990.

29. Yuan, Z.X.; Jing, Z.X.; Hu, R.X. Operation optimization of CCHP-type microgrid considering units' part-load characteristics. In Proceedings of the 2015 IEEE Innovative Smart Grid Technologies-Asia (ISGT ASIA), Bangkok, Thailand, 3-6 November 2015; pp. 1-7.

30. Mao, Y. Study on Climate Adaptability of Human Beings to Thermal Comfort in China. Ph.D. Thesis, Xi'an University of Architecture and Technology, Xi'an, China, 2007.

(C) 2017 by the authors. Licensee MDPI, Basel, Switzerland. This article is an open access article distributed under the terms and conditions of the Creative Commons Attribution (CC BY) license (http:/ / creativecommons.org/licenses/by/4.0/). 